\title{
PTP1B, A Potential Target of Type 2 Diabetes Mellitus
}

\author{
Jia Sun ${ }^{1,2}$, Chao Qu ${ }^{1,2,3}$, Yajun Wang ${ }^{1,2}$, Hui Huang ${ }^{1,2}$, Mingrui Zhang ${ }^{1,2}$, Hongyan Li $^{1,2}$, Yejun Zhang ${ }^{1,2}$, Yang Wang ${ }^{4}$ and Wei Zou ${ }^{1,2^{\star}}$ \\ ${ }^{1}$ College of Life Science, Liaoning Normal University, Dalian 116081, China \\ ${ }^{2}$ Liaoning Key Laboratories of Biotechnology and Molecular Drug Research and Development, Dalian, 116081, China \\ ${ }^{3}$ No. 210 Hospital of Chinese People's Liberation Army, Dalian 116021, China \\ ${ }^{4}$ Department of Medical Microbiology and Immunology, School of Medicine, Creighton University Omaha, NE 68178, China
}

\begin{abstract}
Diabetes is one of the common metabolic diseases, mainly divided into two types, type 1 diabetes mellitus and type 2 diabetes mellitus. Insulin resistance is the main performance of type 2 diabetes mellitus which are relative to some gene mutation, genetics, obesity and so on. Protein-tyrosine phosphatase 1B (PTP1B) plays an important role as a negative regulator in insulin signaling pathways that are implicated in metabolic diseases such as obesity and type 2 diabetes. Many evidences from clinical and basic researches show that the high expression of PTP1B induces insulin resistance. It appears that PTP1B is an effective target for the treatment of type 2 diabetes mellitus. In this review, we briefly introduce composition of PTP1B and the role of PTP1B in insulin signaling of type 2 diabetes mellitus. We also summarized recent research progress of PTP1B inhibitors used in therapy of type 2 diabetes mellitus.
\end{abstract}

\section{Keywords: PTP1B; Type 2 diabetes mellitus; Insulin signaling}

\section{Introduction}

Diabetes is a common metabolic disease which characterized by hyperglycemia, mainly divided into type 1 diabetes mellitus and type 2 diabetes mellitus. Insulin-dependent type 1 diabetes is mostly resulted from the damage of pancreatic $\beta$ cells which makes the absolute lack of insulin; Type 2 diabetes, which is insulin independent, the mainly initial factors are insulin resistance (IR) and relatively lack of insulin. Due to the modern diet and genetic factors, type 2 diabetes mellitus patients have increased in recent years. O'Rahilly et al. predicted that the number of patients with type 2 diabetes mellitus will be more than 300 million by 2025, mainly in developing countries such as India [1-3]. Current treatments for type 2 diabetes mellitus are mostly dependent on insulin and some oral hypoglycemic agents. Long-term insulin injections to patients have a lot of pain and it is inconvenience. The effects of oral hypoglycemic agents are often not satisfied. Therefore, researchers are now looking for more safe and effective drugs and treatments.

The process of tyrosine phosphorylation and dephosphorylation is the basic mechanism of cell growth and differentiation, and the balance of this process was maintained by protein tyrosine phosphatase (PTP) and protein tyrosine kinase (PTK) [4]. PTPs are superfamily of receptor-like and non- transmembrane proteins, whose members are highly specific, tightly regulated and important modulators of cellular signal initiation and termination. Protein tyrosine phosphatase $1 \mathrm{~B}$ (PTP1B) is a key member of the family, a negative regulator in insulin signal transduction [5] and a potential target for treatment of type 2 diabetes mellitus [6]. Therefore, small-molecule PTP1B inhibitors have broad application prospects in the treatment of type 2 diabetes. Here, we briefly introduce composition of PTP1B, the role of PTP1B in insulin signaling of type 2 diabetes mellitus and the research progress of PTP1B inhibitors used in therapy of type 2 diabetes mellitus recently.

\section{PTP superfamily and PTP1B}

The PTP superfamily can be divided into eight subfamilies including tyrosine-specific PTPs, DsPTPs, Cdc25, PTNE, myotubularins, PRL, LMW-PTPs and Cdc14, which are abundant, widely expressed as receptor-like or non-receptor in various cells. PTP1B is a representative of the intracellular PTP which was purified and identified from human placenta by Tonks for the first time in 1988 [7]. PTP1B is encoded by PTPN1 gene and composed of 435 amino acid residues, with PTP family-owned conservative sequence and the molecular weight of 50
$\mathrm{kDa}$. It contains an $\mathrm{N}$-terminal catalytic domain, two proline-rich sequences and a C-terminal hydrophobic region. The active site of PTP1B is located in the P fold of 214-221 residues, in which Cys215 and Arg221 are critical to its phosphatase catalytic sites [8]. PTP1B is localized on the cytoplasmic face of the endoplasmic reticulum (ER) by means of its 35 amino acid C-terminal sequence. The catalytic center in N-terminal containing cysteine and arginine residues is towards to cytoplasm and active PTP1B released from ER after emerging hydrolytic cleavage in C-terminal [9]. Price et al. identified three sensitive areas of type 2 diabetes mellitus chromosome through correlation analysis of gene markers and found that PTPN1 is located in these areas. Bento et al. published PTPN1 SNPs of high resolution map using single nucleotide polymorphism (SNP) [10].

PTP1B is specifically expressed in various human tissues interacted with other members of the PTPs family. In addition, PTP1B function is regulated by several post-translational modifications such as oxitation, nitrosyaltion, sulfyhydration, sumoylation, phosphorylation and proteolytic cleavage. The diverse modifications illustrated the dynamic regulation of this enzyme and its ability to modulate numerous signaling pathways likely in a cell/tissue- and stimulus-dependent manner, with high specificity and precision.

PTP1B, as a potential target for type 2 diabetes and obesity, have expanded out of PTP1B gene cDNA span [11]. At the same time, the molecular dynamics studies of interaction between PTP1B and its inhibitors are also on going [12], all which lay a foundation for screening specific PTP1B inhibitors.

The role of PTP1B in insulin signaling of type 2 diabetes mellitus

The pathogenesis of type 2 diabetes is associated with gene mutation, heredity, obesity and other factors, which main performance is insulin

*Corresponding author: Wei Zou, Liaoning Key Laboratories of Biotechnology and Molecular Drug Research and Development, Dalian, 116081, China, Tel: 86-0411-85827080; E-mail: weizou60@126.com

Received September 01, 2016; Accepted September 13, 2016; Published September 21, 2016

Citation: Sun J, Qu C, Wang Y, Huang H, Zhang M, et al. (2016) PTP1B, A Potential Target of Type 2 Diabetes Mellitus. Mol Biol 5: 174. doi:10.4172/2168 9547.1000174

Copyright: @ 2016 Sun J, et al. This is an open-access article distributed under the terms of the Creative Commons Attribution License, which permits unrestricted use, distribution, and reproduction in any medium, provided the original author and source are credited. 
resistance. Dysfunction of pancreatic $\beta$ cells is one of basic processes and characteristic of the pathogenesis. The increased prevalence of these diseases highlights the urgent need to elucidate the underlying molecular mechanisms to aid in therapeutic intervention.

Insulin secreted from pancreatic $\beta$ cells acts as a major regulator of glucose homeostasis through a complex and integrated signaling network. Insulin receptor is a kind of transmembrane glycoprotein complex molecules, consisting of two alpha and beta subunits by three disulfide bond connection, among which the alpha subunits locate in the lateral of the cell and beta subunits are across the cell membrane. Insulin binding alpha subunits of the receptor induced phosphorylation of tyrosine residues and protein tyrosine kinase (PTK) of beta subunits, and resulted in a series of phosphorylation and dephosphorylation cascade reactions including mitogen-activated protein kinases (MAPK) and PI3K/Akt signal pathways to regulate metabolism. Whereas, when the concentration of insulin is beyond the physiological concentration (hyperinsulinemia), insulin promoted cell proliferation and developments, which may due to the combination of insulin with insulin-like growth factor 1 receptor (IGF-1R) or insulinlike growth factor 1 (IGF-1) hybrid insulin receptor, and had nothing with insulin receptor [13].

Many reports indicate that PTP1B is an established metabolic regulation in mammals and a pharmacological target for type 2 diabetes. During the combination of insulin and its receptor, PTP1B could catalyze insulin receptor (IR) and insulin receptor substrates (IRS) dephosphorylation, coordinated the balance between phosphorylation and dephosphorylation of tyrosine residues, which resulted in downregulation of insulin signal transduction [14]. Besides, PTP1B could dephosphorylate activated JAK2 and STAT3, and prevented leptin signal transduction [15] (Figure 1). High expression of PTP1B influenced the activity of PTKs, which resulted in insulin failing to combine with IR, induced the insulin resistance and leptin resistance, and caused type 2 diabetes and obesity [16,17].
Zabolotny et al. found that, the phosphorylation of insulin receptor tyrosine stimulated by insulin descend by $35 \%$, the activity of PI3K decreased $40-60 \%$ and the activity of protein kinase $\mathrm{C}(\mathrm{PKC})$ that glucose transport required also decreased in overexpressed PTP1B mice muscle compared with the normal mice [18]. Whole-body PTP1B knockout (KO) mice exhibit increased insulin sensitivity and enhanced glucose tolerance $[19,20]$. There is a relationship between occurrence of type 2 diabetes and abnormality lipid metabolism. So far, lots of evidences have confirmed a causal relationship between obesity and insulin resistance in humans and animals. With weight increased, insulin sensitivity and general glucose tolerance decreased [18]. Subsequent studies using tissue-specific knockout mice indicated that body weight, adiposity and leptin action were regulated by neuronal PTP1B. Neuronal PTP1B deficient mice have reduced weight, adiposity, increased activity and energy consumption [21]. It has also been reported that neuronal PTP1B inhibition results in decreased hypothalamic AMP-activated protein kinase (AMPK) activity in peripheral tissues and downstream gene expression changes that promote leanness and increased energy consumption. The mechanism by which PTP1B regulates adiposity and leptin sensitivity is likely to involve the coordinated regulation of AMPK in hypothalamus and peripheral tissues [22]. These results demonstrated a direct role of PTP1B in down regulating the insulin and leptin functioning. These findings sparked interest in developing PTP1B inhibitors for the treatment of type 2 diabetes. Therefore, PTP1B could be used as a potential drug target [23] and provide a new approach for the treatment of type 2 diabetes.

Insulin receptor mediated signal transduction, and participated in a series of cascade reactions in which protein kinase and phosphatase involved, whereas more hypoglycemic targets compounds are associated with insulin signal transduction [24]. They may function by insulin receptor, CytPTK, MAPK, S6 kinases, G protein and cAMP signaling pathway [25]. PTP1B, a member of PTP family, its main function is dephosphorylating the phosphorylated tyrosine residues, insulin receptor and insulin receptor substrates to negative regulate

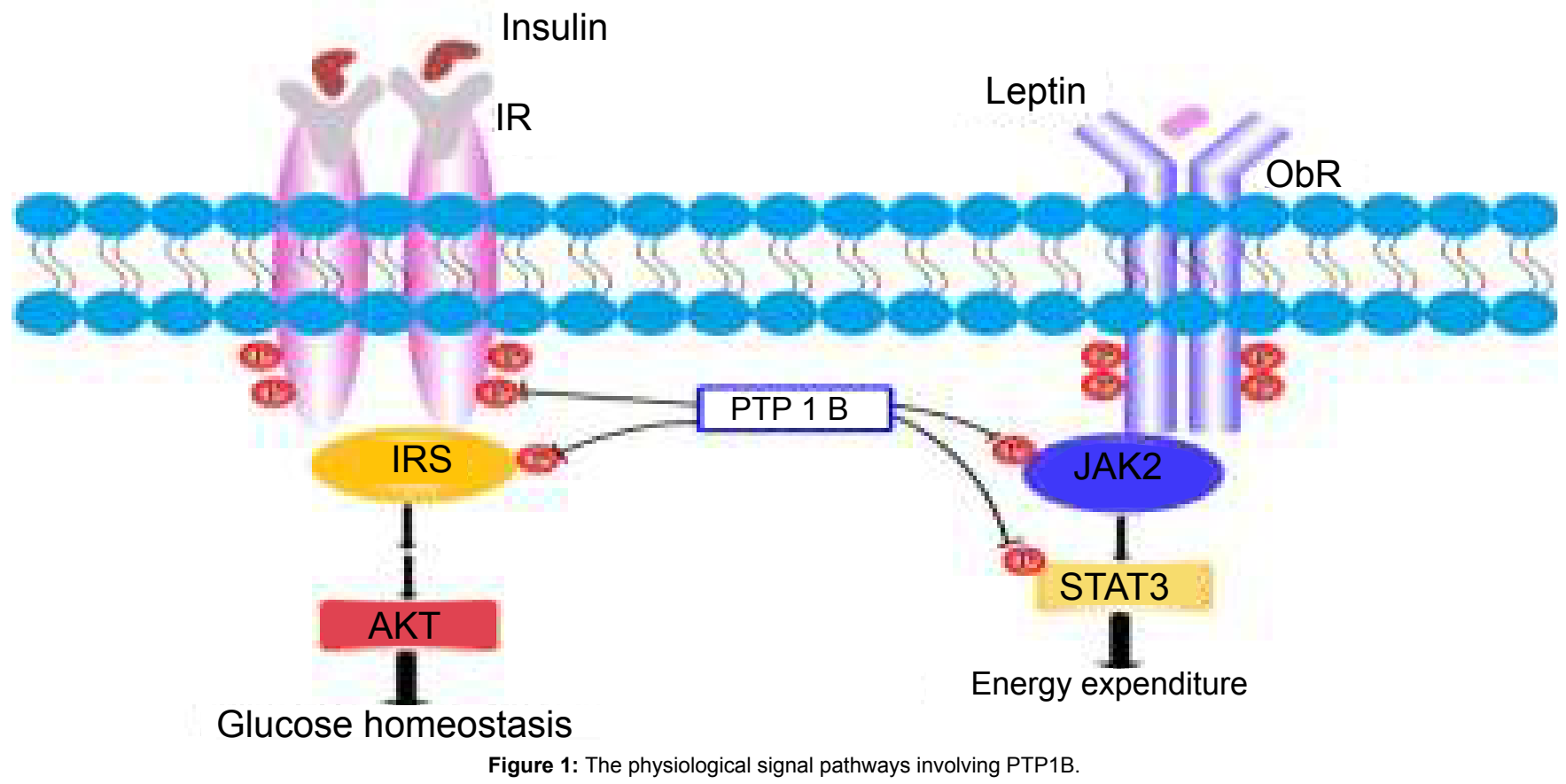


insulin signal transduction. Therefore, PTP1B inhibitors enhance insulin signaling [26,27].

\section{PTP1B inhibitors and therapy of Type 2 diabetes}

PTP1B is an intracellular PTP, involved in negative regulation of insulin as well as leptin signaling. PTP1B has emerged as a validated therapeutic target for the treatment of type 2 diabetes and related metabolic abnormalities [28]. PTP1B has been inhibited experimentally using a variety of mechanisms and chemical entities. PTP1B inhibitors could potentially improve insulin resistance and normalize plasma glucose and insulin level without inducing hypoglycemia [29].

Synthetic PTP1B inhibitor and therapy of Type 2 diabetes: Recent years, many pharmaceutical companies have developed various PTP1B inhibitors as drug candidates for therapy of Type 2 diabetes in clinical trials, including ertiprotafib, ISIS 113715, ISIS-PTP1BRx and trodusquemine [30]. In addition, some new synthetic PTP1B inhibitors were reported such as Benzofuran and benzothiophene biphenyls, Vanadium complexes and Aminobenzoic acid.

Thiazolidinediones (TZDs) are commonly known as glitazones that share a common molecular scaffold 2, 4-TZDs. Compound 28 discovered by Koyama et al. exhibited comparable levels of glucose correction to rosiglitazone in $\mathrm{db} / \mathrm{db}$ mouse type 2 diabetes animal model (Figure 2A) [31]. In addition, TZDs could correct hyperglycemia by enhancing insulin sensitivity in target tissues and were shown to improve glycemic control by ameliorating insulin resistance in both peripheral tissues and liver in type 2 diabetic patients [32]. Clinical research showed that metformin therapy in patients with type 2 diabetes combined with TZDs could reduce the risk of treatment failure [33]. TZDs lower glycosylated hemoglobin (HbA1c) levels more effectively than GLP-1 mimetics or dipeptidyl peptidase IV (DPP IV) inhibitors and achieve greater durability than biguanides [34]. However, the side effect and safety profiles of peroxisome proliferator-activated receptor- $\gamma$ (PPAR- $\gamma)$ as a class have come into question [35]. The marketing of TZDs was severely restricted in 2011 [36].
Mimetics of pTyr are starting points for the design of competitive PTP1B inhibitors, containing a carboxylic or phosphonic acid and a large lipophilic tail. Rakse et al. reported a novel 3-acetamido-4-methyl benzoic acid derivatives as pTyr mimetics, the most potent compound 10 showed PTP1B predominantly inhibited activity (Figure 2B) [37,38]. Benzofuran and benzothiophene biphenyls act at the catalytic site of the enzyme to modulate its activity. Malamas et al. identified two novel series of benzofuran/benzothiophene biphenyl, oxo-acetic acids and sulfonyl-salicylic acids as potent PTP1B inhibitors with good oral antihyperglycemic activities (Figure 2C) [39]. Further, Murthy and Kulkarni performed 3D-QSAR study using CoMFA and CoMSIA of the above series. Comparison of 3D-QSAR contour maps with steric, electrostatic and hydrophobic properties of the PTP1B enzyme showed a high level of compatibility [40]. Vanadium complexes have insulinmimetic effects and can be used to treat complications of diabetes. Vanadate and pervanadate (the complexes of vanadate with hydrogen peroxide) are two commonly used general PTP inhibitors [41,42]. Our previous study synthesized a new oxovanadium complex with 3,5-dimethyl-pyrazolyl ligand, $\mathrm{VO}(\mathrm{HB}(3,5-\mathrm{Me} 2 \mathrm{pz}) 3)(3,5-\mathrm{Me} 2 \mathrm{pz})$ $(\mathrm{SCN})(\mathrm{SCNH}) 2$, showed low toxicity and significantly reduced blood glucose, blood urea nitrogen and serum creatinine levels in the diabetic mice (Figure 2D). Additionally, p42/p44MAPK and Akt phosphorylation was markedly increased in diabetic mice and was decreased by treatment with the new oxovanadium complex [43]. Aminobenzoic acid compound is a phospholipid mimetics inhibitor which directly obtained by high throughput screening method. Such compounds belong to reversible competitive inhibitor proved by enzyme kinetics and co-crystallization. Zhou et al. demonstrated that 2-(oxalylamino) benzoic acid inhibitors in the active site of PTP1B by means of molecular docking and CoMFA [44]. Zhang et al. indicated that CX08005 was a competitive inhibitor of PTP1B by binding to the catalytic P-loop through hydrogen bonds (Figure 2E) [45]. In addition, various other classes of compounds have been reported to have PTP1B inhibitory potential, including isothiazolinones [46], paracaseolide A analogs [47], terpenoids [48] and many more groups that show PTP1B inhibitory activity $[49,50]$ (Figure 2).
A

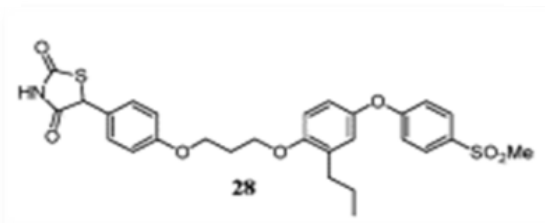

$\mathrm{D}$

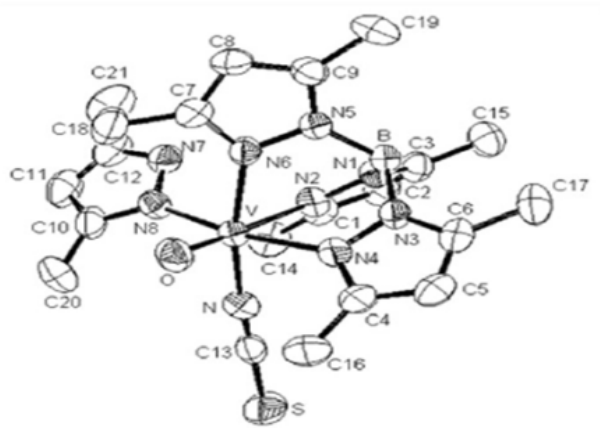

C

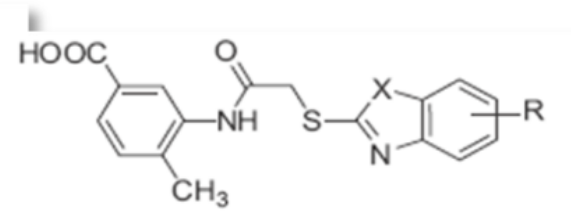

$\mathrm{E}$

Figure 2: Chemical structures of several synthetic PTP1B inhibitors. 
A

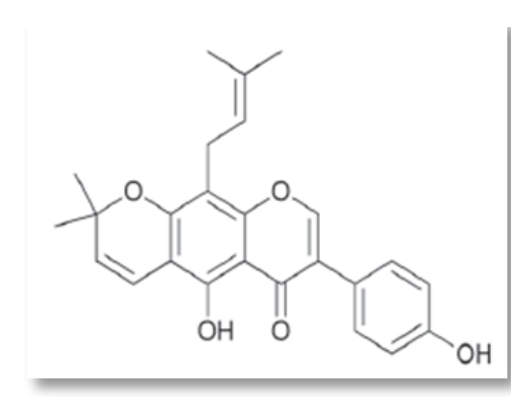

B

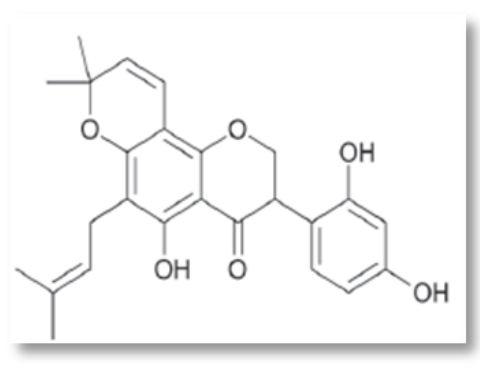

$\mathrm{C}$

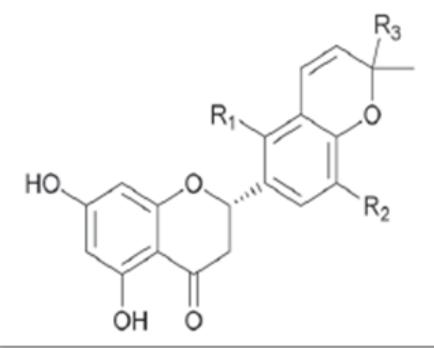

$\mathrm{D}$<smiles>CC(C)=CC(=O)c1oc2cc(C)ccc2c1C</smiles>

$\mathrm{E}$

Figure 3: Chemical structures of several natural molecular PTP1B inhibitors

Natural molecules as PTP1B inhibitor and therapy of Type 2 diabetes: Creatures of nature synthesized a variety of novel structure and secondary metabolites during biological evolution. Secondary metabolites contain structural diversity and kind medicinal properties and many drugs are directly or indirectly derived from natural products. What's more, secondary metabolites will continue to serve as new drugs. Therefore, natural products are considered as important sources for new drugs for PTP1B inhibitors [51]. A wide variety of natural products have been reported with PTP1B inhibitory activity such as Morphinane alkaloid, Flavonoid, Terpenoids and so on.

Morphinane alkaloid, a kind of nitrogenous alkaline organic compound and an effective ingredient in alkaloids, is important active component in Chinese herbal medicine which widely exists in nature. It was demonstrated that berberineome, papaverine and flavonoid are all effective anti-diabetic herb through inhibiting PTP1B [52,53] and significantly reducing the fasting blood glucose levels [54]. Flavonoid isolated from Glycyrrhiza inflata, Cyclocarya paliurus and Pongamia pinnata can also inhibit PTP1B activities (Figures 3A-3C) $[55,56]$. Terpenoids as organic compounds distribute in plants, animals and marine life, significantly inhibited the activity of PTP1B (PTP1B) (Figures 3D and 3E) [57-60]. In addition, PTP1B inhibitory activity were also shown in proteoglycan, quinolone, steroids, containing nitrogen or sulfur compounds for anti-diabetes [61-63].

In summary, it was found that PTP1B is the critical negative regulator in insulin signaling pathway, and plays an important role in the pathogenesis of type 2 diabetes mellitus. The development of smallmolecule drugs for PTP1B (obtained from herb or synthetic) maybe has a good future for the treatment of type 2 diabetes mellitus $[64,65]$.

\section{Acknowledgement}

This project was supported by the National Natural Science Foundation of China (No. 30970353) and Science and Technology Plan Projects in Liaoning Province, China (No. 2015020568).

\section{References}

1. O'Rahilly S, Barroso I, Wareham NJ (2005) Genetic factors in type 2 diabetes: The end of the beginning? Science 307: 370-373.

2. Lowell BB, Shulman GL (2005) Mitochondrial dysfunction and type 2 diabetes Science 307: 384-387.

3. Shaw JE, Sicree RA, Zimmet PZ (2010) Global estimates of the prevalence of diabetes for 2010 and 2030. Diabetes Res Clin Pract 87: 4-14.

4. Soulsby M, Bennett AM (2009) Physiological signaling specificity by protein tyrosine phosphatases. Physiology (Bethesda) 24: 281-289.

5. Panzhinskiy E, Ren J, Nair S (2013) Pharmacological inhibition of protein tyrosine phosphatase 1B: A promising strategy for the treatment of obesity and type 2 diabetes mellitus Curr Med Chem 20: 2609-2625.

6. Qin Z, Pandey NR, Zhou X, Stewart CA, Hari A, et al. (2015) Functional properties of Claramine: A novel PTP1B inhibitor and insulin-mimetic compound. Biochem Biophys Res Commun 458: 21-27.

7. Tonks NK, Diltz CD, Fischer EH (1988) Purification of the major proteintyrosine-phosphatases of human placenta. J Biol Chem 263: 6722-6730.

8. Shah MR, Ishtiaq Hizbullah SM, Habtemariam S, Zarrelli A, Muhammad A, et al. (2015) Protein tyrosine phosphatase 1B inhibitors isolated from Artemisia roxburghiana. J Enzyme Inhib Med Chem 29: 1-5.

9. Frangioni JV, Beahm PH, Shifrin V, Jost CA, Neel BG (1992) The nontransmembrane tyrosine phosphatase PTP-1B localizes to the endoplasmic reticulum via its 35 amino acid C-terminal sequence Cell 68: 545-560.

10. Bento JL, Palmer ND, Mychaleckyj JC, Lange LA, Langefeld CD, et al. (2004) Association of protein tyrosine phosphatase $1 \mathrm{~B}$ gene polymorphisms with type 2 diabetes. Diabetes 53: 3007-3012.

11. Lu YX, Li J, Zhang Q, Xu YH, Chen B, et al. (2008) Cloning and expression of human PTP1B cDNA in E. coli. Chinese Pharmacologial Bulletin 24: $91-95$ (in Chinese).

12. Wang JF, Gong K, Wei DQ, Li YX, Chou KC (2009) Molecular dynamics studies on the interactions of PTP1B with inhibitors: From the first phosphate-binding site to the second one. Protein Eng Des Sel 22: 349-355.

13. Rajala RV, Basavarajappa DK, Dighe R, Rajala A (2013) Spatial and temporal aspects and the interplay of Grb14 and protein tyrosine phosphatase-1B on the insulin receptor phosphorylation. Cell Commun Signal 11: 96. 
14. Salmeen A, Andersen JN, Myers MP, Tonks NK, Barford D (2000) Molecula basis for the dephosphorylation of the activation segment of the insulin receptor by protein tyrosine phosphatase 1B. Mol Cell. 6: 1401-1412

15. Lund IK, Hansen JA, Andersen HS, Møller NP, Billestrup N (2005) Mechanism of protein tyrosine phosphatase 1B-mediated inhibition of leptin signalling. $J$ Mol Endocrinol. 34: 339-351.

16. He RJ, Yu ZH, Zhang RY, Zhang ZY (2014) Protein tyrosine phosphatases as potential therapeutic targets. Acta Pharmacol Sin 35: 1227-1246.

17. Barr AJ (2010) Protein tyrosine phosphatases as drug targets: Strategies and challenges of inhibitor development. Future Med Chem 2: 1563-1576.

18. Zabolotny JM, Haj FG, Kim YE, Kim HJ, Shulman GI, et al. (2004) Transgenic overexpression of protein-tyrosine phosphatase $1 \mathrm{~B}$ in muscle cause insulin resistance, but overexpression with leukocyte antigen-related phosphatase does not additively impair insulin action. J Biol Chem 279: 24844-24851.

19. Cheng A, Uetani N, Simoncic PD, Chaubey VP, Lee-Loy A, McGlade CJ, et al. (2002) Attenuation of leptin action and regulation of obesity by protein tyrosine phosphatase 1B. Dev Cell 2: 497-503.

20. Haj FG, Zabolotny JM, Kim YB, Kahn BB, Neel BG (2005) Liver-specific proteintyrosine phosphatase 1B (PTP1B) re-expression alters glucose homeostasis of PTP1B-/- mice. J Biol Chem 280: 15038-15046.

21. Bence KK, Delibegovic M, Xue B, Gorgun CZ, Hotamisligli GS, et al. (2006) Neuronal PTP1B regulates body weight, adiposity and leptin action. Nat Med 12: $917-924$

22. Martin TL, Alquier T, Asakura K, Furukawa N, Preitner F, et al. (2006) Dietinduced obesity alters AMP kinase activity in hypothalamus and skeletal muscle. J Biol Chem 281: 18933-18941.

23. Koren S, Fantus IG (2007) Inhibition of the protein tyrosine phosphatase PTP1B: Potential therapy for obesity, insulin resistance and type-2 diabetes mellitus. Best Pract Res Clin Endocrinol Metab 21: 621-640.

24. Zhang S, Zhang ZY (2007) PTP1B as a drug target: Recent developments in PTP1B inhibitor discovery. Drug Discov Today 12: 373-381.

25. Erbe DV, Klaman LD, Wilson DP, Wan ZK, Kirincich SJ, et al. (2009) Prodrug delivery of novel PTP1B inhibitors to enhance insulin signaling. Diabetes Obes Metab 11: 579-588.

26. Lee S, Wang Q (2007) Recent development of small molecular specific inhibitor of protein tyrosine phosphatase 1B. Med Res Rev. 27: 553-573.

27. Tsuchiya A, Kanno T, Nagaya H, Shimizu T, Tanaka A, et al. (2014) PTP1B inhibition causes Rac1 activation by enhancing receptor tyrosine kinase signaling. Cell Physiol Biochem 33: 1097-1105.

28. Zhang ZY, Lee SY (2003) PTP1B inhibitors as potential therapeutics in the treatment of type 2 diabetes and obesity. Expert Opin Investig Drugs 12: 223-233.

29. Liu G (2003) Protein tyrosine phosphatases 1B (PTP 1B) inhibition: Opportunities and challenges. Curr Med Chem 10: 1407-1421.

30. Henry SP, Johnson M, Zanardi TA, Fey R, Auyeung D, et al. (2012) Renal uptake and tolerability of a 2'-O-methoxyethyl modified antisense oligonucleotide (ISIS 113715 ) in monkey. Toxicology. 301: 13-20.

31. Koyama H, Boueres JK, Han W, Metzger EJ, Bergman JP, et al. (2003) 5-Aryl thiazolidine-2,4-diones as selective PPAR-g agonists. Bioorg Med Chem Lett 13:1801-1804

32. Mudaliar S, Henry RR (2001) New oral therapies for type 2 diabetes mellitus: The glitazones or insulin sensitizers. Annu Rev Med 52:239-257.

33. Mamza J, Mehta R, Donnelly R, Idris I (2016) Important differences in the durability of glycaemic response among second-line treatment options when added to metformin in type 2 diabetes: A retrospective cohort study. Ann Med 48: 224-234

34. Nathan DM, Buse JB, Davidson MB, Ferrannini E, Holman RR, et al. (2009) Medical management of hyperglycemia in Type 2 diabetes: A consensus algorithm for the initiation and adjustment of therapy a consensus statement of the American Diabetes Association and the European Association for the Study of Diabetes. Diabetes Care 32: 193-203.

35. Qian S, Zhang M, He Y, Wang W, Liu S (2016) Recent advances in the development of protein tyrosine phosphatase 1B inhibitors for Type 2 diabetes. Future Med Chem. 8:1239-1258.

36. Tolman KG (2011) The safety of thiazolidinediones. Expert Opin Drug Saf 10: 419-428.
37. Rakse M, Karthikeyan C, Deora GS, Moorthy NS, Rathore V, et al. (2013) Design, synthesis and molecular modelling studies of novel 3-acetamido-4 methyl benzoic acid derivatives as inhibitors of protein tyrosine phosphatase 1B. Eur J Med Chem 70: 469-476.

38. Tang YB, Liu JZ, Zhang SE, Du X, Nie F, Tian JY, et al. (2014) 3-Phenylpropanoic acid-based phosphotyrosine (pTyr) mimetics: Hit evolution to a novel orally active protein tyrosine phosphatase 1B (PTP1B) inhibitor. ChemMedChem 9 918-921.

39. Malamas MS, Sredy J, Moxham C, Katz A, Xu W, et al. (2000) Novel benzofuran and benzothiophene biphenyls as inhibitors of protein tyrosine phosphatase $1 \mathrm{~B}$ with antihyperglycemic properties. J Med Chem 43: 1293-1310.

40. Murthy VS, Kulkarni VM (2002) 3D-QSAR CoMFA and CoMSIA on protein tyrosine phosphatase 1B inhibitors. Bioorg Med Chem 10: 2267-2282.

41. Brichard SM, Henquin JC (1995) The role of vanadium in the management of diabetes. Trends Pharmacol Sci 16: 265-270.

42. Fantus IG, Kadota S, Deragon G, Foster B, Posner BI (1989) Pervanadate (peroxide(s) of vanadate) mimics insulin action in rat adipocytes via activation of the insulin receptor tyrosine kinase. Biochemistry 28: 8864-8871.

43. Liu Y, Chen DD, Xing YH, Ge N, Zhang Y (2014) A new oxovanadium complex enhances renal function by improving insulin signaling pathway in diabetic mice. J Diabetes Complications 2: 265-272.

44. Zhou M, Ji M (2005) Molecular docking and 3D-QSAR on 2-(oxalylamino) benzoic acid and its analogues as protein tyrosine phosphatase $1 \mathrm{~B}$ inhibitors. Bioorg Med Chem Lett 15: 5521-5525.

45. Zhang X, Tian J, Li J, Huang L, Wu S, et al. (2016) A novel protein tyrosine phosphatase $1 \mathrm{~B}$ inhibitor with therapeutic potential for insulin resistance. $\mathrm{Br} \mathrm{J}$ Pharmacol 173: 1939-1949.

46. Combs AP, Yue EW, Bower M, Ala PJ, Wayland B, et al. (2005) Structure-based design and discovery of protein tyrosine phosphatase inhibitors incorporating novel isothiazolidinone heterocyclic phosphotyrosine mimetics. J Med Chem 48: 6544-6548

47. Yin JP, Tang CL, Gao LX, Ma WP, Li JY, et al. (2014) Design and synthesis of paracaseolide $\mathrm{A}$ analogues as selective protein tyrosine phosphatase 1B inhibitors. Org Biomol Chem 12: 3441-3445.

48. Jin T, Yu H, Huang XF (2016) Selective binding modes and allosteric inhibitory effects of lupane triterpenes on protein tyrosine phosphatase 1B. Sci Rep 6 : 20766.

49. Ma $Y$, Jin $Y Y$, Wang $Y L$, Wang $R L$, Lu XH, et al. (2014) The discovery of novel and selective inhibitor of PTP1B over TCPTP: 3D QSAR pharmacophore modeling, virtual screening, synthesis and biological evaluation. Chem Biol Drug Des 83: 697-709.

50. Panzhinskiy E, Ren J, Nair S (2013) Pharmacological inhibition of protein tyrosine phosphatase 1B: A promising strategy for the treatment of obesity and type 2 diabetes mellitus. Curr Med Chem 20: 2609-2625.

51. Koehn FE, Carter GT (2005) The evolving role of natural products drug discovery. Nat Rev Drug Discov 4: 206-220.

52. Bustanji Y, Taha MO, Yousef AM, Al-Bakri AG (2006) Berberine potently inhibits protein tyrosine phosphatase 1B: Investigation by docking simulation and experimental validation. J Enzyme Inhib Med Chem 21: 163-171.

53. Chen C, Zhang Y, Huang C (2010) Berberine inhibits PTP1B and mimics insulin action. Biochem Biophys Res Commun 397: 543-547.

54. Li ZH, Guo H, Xu WB, Ge J, Li X, et al. (2016) Rapid identification of flavonoid constituents directly from PTP1B inhibitive extract of raspberry (Rubus idaeus L.) leaves by HPLC-ESI-QTOF-MS-MS. J Chromatogr Sci 54: 805-810.

55. Zhang J, Shen Q, Lu JC, Li JY, Liu WY, et al. (2010) Phenolic compounds from the leaves of Cyclocarya paliurus (Batal.) ljinskaja and their inhibitory activity against PTP1B. Food Chem 119: 1491-1496.

56. Jiang CS, Liang LF, Guo YW (2012) Natural products possessing protein tyrosine phosphatase 1B (PTP1B) inhibitory activity found in the last decades. Acta Pharmacol Sin 33: 1217-1245.

57. Tao QQ, Ma K, Bao L, Wang K, Wang K (2016) Sesquiterpenoids with PTP1B inhibitory activity and cytotoxicity from the edible mushroom Pleurotus citrinopileatus. Planta Med 82: 639-644.

58. Lee JS, Maarisit W, Abdjul DB, Yamazaki H, Takahashi O, et al. (2016) Structures and biological activities of triterpenes and sesquiterpenes obtained from Russula lepida. Phytochemistry 9422: 30043-30047. 
59. Wu WB, Zhang H, Dong SH, Sheng L, Wu Y, et al. (2014) New triterpenoids with protein tyrosine phosphatase $1 \mathrm{~B}$ inhibition from Cedrela odorata. J Asian Nat Prod Res 16: 709-716.

60. Liang LF, Kurta'n T, Ma'ndi A, Yao LG, Li J (2013) Unprecedented diterpenoids as a PTP1B inhibitor from Hainan soft coral Sarcophyton trocheliophorum Marenzeller. Org Lett 15: 274-277.

61. Zhao JX, Shi SS, Sheng L, Li J, Yue JM (2015) Terpenoids and steroids from Euphorbia hypericifolia. Nat Prod Commun 10: 2049-2052.

62. Tamrakar AK, Maurya CK, Rai AK (2014) PTP1B inhibitors for type 2 diabetes treatments: A patent review (2011-2014). Expert Opin Ther Pat 24: 1101-1115.
63. Zeng $\mathrm{K}$, He YN, Yang D, Cao JQ, Xia XC, et al (2014) New compounds from acid hydrolyzed products of the fruits of Momordica charantia L. and their inhibitory activity against protein tyrosine phosphatase 1B. Eur J Med Chem 81: $176-180$.

64. Yin WW, Chen Z, Tang YB, Ye F, Tian JY, et al. (2014) SAR of benzoyl sulfathiazole derivatives as PTP1B inhibitors. Acta Pharmaceutica Sinica 49: $632-628$.

65. Liu ZQ, Liu T, Chen C, Li MY, Wang ZY, et al. (2015) Fumosorinone, a nove PTP1B inhibitor, activates insulin signaling in insulin-resistance HepG2 cells and shows anti-diabetic effect in diabetic KKAy mice. Toxicol Appl Pharmacol 285: $61-70$. 